\title{
LA LECTOESCRITURA VISUAL EN EL PUEBLO ASHÁNINKA A TRAVÉS DE LOS CUENTOS
}

\author{
Rudi Camañari Quinchori ${ }^{1}$ \\ Universidad Nacional Mayor de San Marcos-EILA \\ rudi.camanari@unmsm.edu.pe \\ (1) https://orcid.org/0000-0002-7347-6240
}

\section{Resumen}

El presente artículo tiene como finalidad reconocer a la lectoescritura visual como una estrategia importante para valorar las narraciones míticas de la tradición oral asháninka y de lo trascendental que son como medio de transmisión de valores, ideas y costumbres en las comunidades. A partir de los relatos míticos y las historias de los sabios asháninka que son transmitidos a los padres y a su vez a sus hijos se está realizando el intercambio de estos saberes que permitirán identificar aquello que está alrededor de una imagen. Entonces, la lectoescritura audiovisual buscará incrementar el hábito lector en las comunidades a partir de las imágenes y las historias que existen alrededor de ellas sensibilizando

1 Este trabajo recoge los avances de mi tesis de maestría en Educación Intercultural Bilingüe del Posgrado de Letras de la UNMSM y las indagaciones sobre literatura indígena que desarrollo en el grupo de investigación Discursos, Representaciones y Estudios Interculturales (EILAUNMSM: E21031271). 
a los adultos, jóvenes, adolescentes y sobre todo los niños y niñas del pueblo asháninka de la Selva Central. Esta investigación es necesaria porque a través de las imágenes se identificará las historias ancestrales y relatos míticos que existe a su alrededor y usarlas como un insumo de la lectoescritura visual.

Palabras claves: Lectoescritura visual; Asháninka; Tradición oral

\section{Summary}

The purpose of this article is to recognize visual literacy as an important strategy to value the mythical narratives of the Ashaninka oral tradition and how transcendental they are as a means of transmitting values, ideas and customs in communities. From the mythical stories and the stories of the Asháninka sages that are transmitted to the parents and in turn to their children, the exchange of this knowledge is taking place that will allow to identify what encompasses an image. Thus, audiovisual literacy will seek to improve the reading habits in the communities with the images and stories about their surroundings, sensitizing adults, young people, adolescents and especially the children of the Ashaninka people of the Selva Central. This research is necessary because through the images we identify the ancestral and mythical stories that exist around them and use them as an input for visual literacy.

Keywords: Ashaninka; Oral tradition; Visual literacy

\section{Introducción}

La lectoescritura audiovisual que planteo como estrategia didáctica desde mi práctica docente permite afianzar en los estudiantes asháninka la lectoescritura de la lengua originaria. Para desarrollar la lectoescritura audiovisual en los estudiantes se ha propuesto usar los relatos que tiene el pueblo asháninka; de los cuales se ha seleccionado solo dos: Tisoni que es un relato que marca el liderazgo y control del territorio asháninka, y Nabireri, que es un cuento que explica el origen y la transformación del universo, ambos contados por Amadeo Barboza de la comunidad de Otari. Los relatos míticos tienen un gran contenido cultural que representan el origen de la historia y los valores que genera en los estudiantes. Para la presente investigación, la lectoescritura audiovisual trata de la enseñanza de la lectura y escritura a través de recursos audiovisuales como las imágenes y textos orales que son 
escuchados por los niños y las niñas. Es necesario señalar que estos materiales (imágenes y narraciones orales) son preparados por la docente de Eduación Intercultural Bilingüe (EIB).

\section{Literatura oral asháninka}

La literatura oral asháninka es el conjunto de textos literarios que se encuentran en la memoria colectiva y son transmitidos de forma oral de generación en generación, de los curanderos, chamanes, etc., internamente, en una comunidad (AIDESEP 2003). La literatura oral nace sobre las diferentes formas de preescrituras hechas en huellas impregnadas en las rocas, piedras, en los tallados a madera, en las hojas de las plantas que se observan como imágenes. En ese espacio, se interpreta diversos contextos cotidianos propios que revelan la supervivencia del ser y luego aquello, pasa a convertirse en historias, relatos, cuentos y mitos del pueblo (Juárez Rutty 2010).

La literatura del pueblo asháninka está conformado por relatos míticos cosmogónicos, relatos míticos culturales, relatos míticos de origen, relatos míticos de seres sobrenaturales, relatos míticos de transformaciones y relatos míticos ejemplares-explicativos (Jacinto Santos 2021). En la actualidad, los que transmiten esta forma literaria son los sabios (ancianos), docentes bilingües (compiladores, recolectores), pintores, vaporadoras, etc. Estas historias que fueron reales en el pasado, al ser contadas de generación en generación, han adquirido la forma de leyenda y mito y se depositan en los relatos míticos. Los recopiladores cumplimos la función de difusión cultural de nuestra oralidad.

\section{Corpus de la literatura oral asháninka}

Para elegir el corpus de literatura oral de nuestra investigación se ha elegido la clasificación arawak de Jacinto Santos (2015: 147) propuesta que refleja el contenido cultural del pueblo asháninka donde el autor analiza la estructura interna que contiene los relatos míticos, cuentos, mitos orales y leyendas. Lo dicho hasta aquí supone que la narración elegida de manera oral encaja en la propuesta del autor nativo. A continuación, mostramos la propuesta: 


\section{Tradición oral}

$\Rightarrow$ 1. Relato mítico cosmogónico (ca)

$\Rightarrow$ 2. Relato mítico cultural

$\Rightarrow$ 3. Relato mítico de origen

$\Rightarrow$ 4. Relato mítico de seres sobrenatural

$\Rightarrow$ 5. Relato mítico de transformaciones

$\Rightarrow$ 6. Relato mítico ejemplares-explicativos

\section{Literatura oral asháninka}

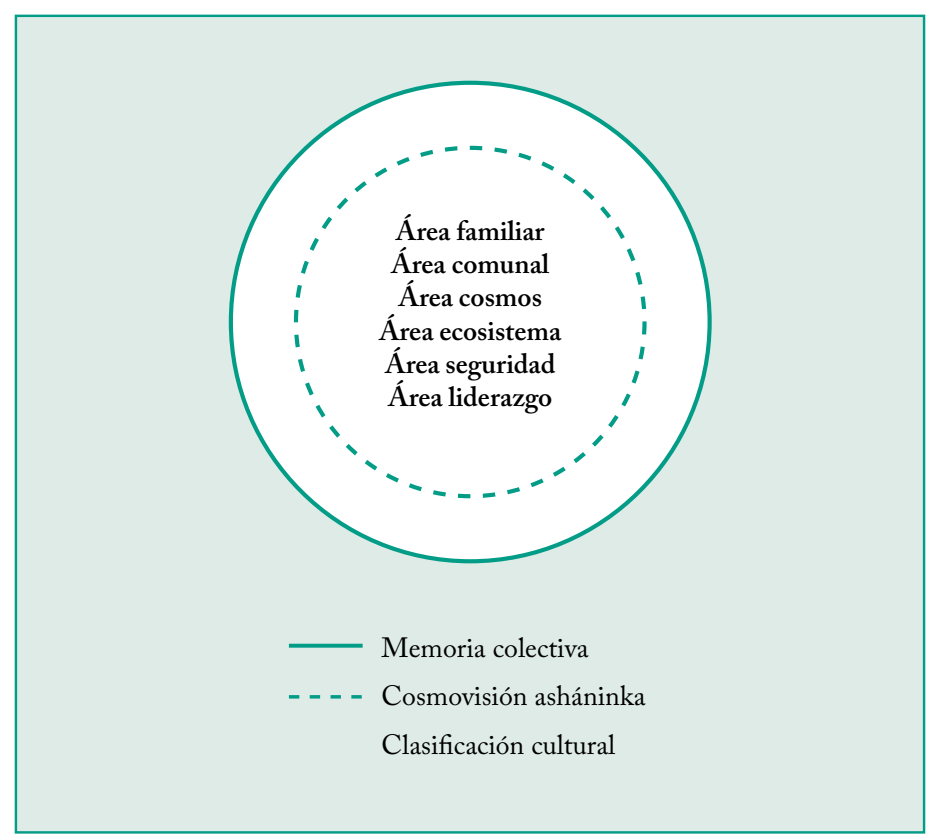

Fuente: Jacinto Santos, 2021 
Esta propuesta nos lleva a conocer las formas del narrar del pueblo asháninka que comparte áreas o espacios como familiar, comunal, cosmos, ecosistema, seguridad y liderazgo. Estas áreas tienen su correlato con el 'relato mítico' cosmogónico, cultural, de origen, de seres sobrenaturales, de transformaciones y de ejemplares-explicativos.

La variedad de los 'relatos míticos' que proponemos analizar tienen diversas características en su composición interna de la frase narrativa que son: frase de entrada recurrente y frase de salida que por el momento son los más visibles.

La selección de nuestros cuentos titulado Tisoni y Nabireri se ubica en la clasificación dentro del área de ecosistema y el área de cosmos. Por otro lado, si a estos relatos míticos los denominamos mitos o tradiciones orales (Vilchez Jimenez 2003), la clasificación que llevan estos relatos míticos de Tisoni y Nabireri serán de transformación y de ser sobrenatural. El lugar donde se recopiló este relato mítico fue en la comunidad de Otari y lo contó el señor 'Amadeo Barboza'. Aquí presentamos los relatos míticos:

\section{Tisoni}

Perani yatiribetani tisoni isaike itsipataro ijina, irishirishinto jeri ishaninkape, irika shirampari osheki inebetaro ikomintsati, aririka ijate antamiki ikomintsati osheki japinti apani atiri, ari ipiaje eiro ipiyaja janakerira, ipeyakia maba kitaiteri jamaje ibatsa osheki shikotaka, okantabetyari ijina jokame iti pamajeitake ababakiata, ikantanake te nobakari antamiki, ari ikantapinitatya. Aparoni kitaiteri ikantiri iranire sheripiari aní noijatanakemi anta akomintsati, ari ibetsikajeitanake, jati, yaretaka antamiki ikanti iranire aní ari asaikeri jaka, eiro pijati janta kariperori oni, ari yakanake iranire sheripiari, impoiji ira tisoni jake osheki chichi oijake, irosati jamenakeri, iranire, pipiyataka jayi nija, ikenkishiyanaka ¿paita ikantantanari eiro pijati anta? Nomenaiteta ijatake shintsi, yamenake osheki iito atiri kenitake, itsarobanake kapichaji, saikapaje. Oshabijitanaki, ainiro antyaro mapi ikantiri aní pimaye jaka, ari yakanake, irirori irosati isaki pamariki, nariaka sheripiarira, sheee, ipokake ikantiri aní makemi tekerata, piyanaja pamari impoiji ipiya isampitapakeri aní makemi tekerata, ikenkishaka namatabiteri nomaye, ipiaja isampitapajeri, te jakeri maba japitakero, ikenkishiriaka make yanake antyaro mapi ishapekiri, yokirianake iranire aní paita panterika, ijokanakero imapine, ikantashitanaka masabirentsi, masabirentsi, ikatianaja iranire ikisanakeri, jataje inampiki ikantapajero iritsiro pijimeranki osheki ibayeti atiri irinti abapintari, kisanaka ijina oyakotajeri ipokaje, irirori iposhikitanaje te ipokaje shintsi, ipokantajari abisake kitaiterikipe, oñabajatiri ijina shiriri, te ikonkaje ikemitapinta, ipaitantyariri piarentsi, okisabakeri, ikantanake je naro tisoni yaranake ikenanakero inchatoshiki.

Ashitarori: Amadeo Barboza 


\section{Nabireri}

Perani irobakera yobetsikantanakarori Tasorentsi kipatsi yatiribaetani Nabireri, tekatsi ikanta iriperori Ashaninka, ishintsikane aisati itasonkanti yanitironi kipatsi. Apararoni kitaiteri ijatake yanibaeti, tema itiyankakeri tasorentsi yobetsikeri Ashaninkapaye, Piratsipaye kari timayetatsiri; yaniti, yaniti, imakotake yamenanontaka inchatoki antaro ari isaikake omentaki itintakaro, te osamanaiteji imanake. Ikanta ipokashitakeri Samani yamake iyanire yobapakaro, imitaji, imitaji yobeshiriaka ipantsake shintsini, te yamayaji timatsi Ashaninka imayi. Ari itinanaka Nabireri ipitsokanaka aisati ikisanaka yamenakeri sorerereee. Ari iñanatakeri ¡Abiro tinakenari! Pibajiro Samani Osheki piñamataro kaniri. Nimaeka pashaninkate, itsonkakero iñanati atiritanake katiyanaka aisati pipajitya Ashaninka; pinkantyani antabaerenti, kobintsanti, shimabaerenti aisati obayeri. Abiro notsipabintsare, anibaetero kipatsi, ikanta itsipatanakari, aotsiki iñakeri jananeki yataitiro inchato, Nabireri iñanatiri. Irinti koshiri shiyanaka koshiritanake, ari ikantarini Osheki ipeayetiri atiripaye piratsi. Iroñaka atiripaye iyotaneke te ishinetajeri ishitobaje itomipaye aotsiki aisati iñatsabetya ishiyajeitanaka arejiki. Ari meka Nabireri yobashiretanaka isaikanake apaniroeni irinti iñeri itsipabintsare Ashaninka. Ari ikenkishiriaka ikantiri Ashaninka, tsame aretyaro otsipa nampitsi. Iroñaka yanitanake inchatomashiki akeri antaro itashe, ironti yoba otsoba tsirentsi, kamona, kepiashi aisati kipatsi. Te itsinampa yataitakero Osheki otishi. Ari ikantiri itsipabintsare, Pamero ironta tema kachari, Ashaninka yakanake ¡je! Irotake. Iroñaka yobeshiriaka, ikantiri otimatye aretyaro nampitsi. Ari okaratsi.

Ashitarori: Amadeo Barboza

\section{Lectoescritura y la educación asháninka}

Teniendo como recursos diferentes imágenes, se busca que los estudiantes se familiaricen, para que a través de secuencias, grafiquen la escritura de oraciones, palabras y letras de la L1. Luego, la docente propone una secuencia de imágenes contextualizadas del relato mítico "Tisoni" que el estudiante observará e imaginará para armar su lectura visual (imaginando lo que el relato narra) y, luego, compartirá lo imaginado explicando la secuencia de imágenes, para al final escribirlo en lengua asháninka. Finalmente, los niños y niñas construirán su relato mítico con palabras nuevas, elaborando sus dibujos y lo colocarán en un espacio a la vista de sus compañeros para que lo lean e interpreten.

Siguiendo esta secuencia, los niños y niñas van adquiriendo las competencias para leer y escribir en la lengua asháninka; a su vez, están compartiendo conocimientos en su propia lengua y cultura asháninka. Todas estas habilidades que desarrollan los estudiantes mediante las imágenes y las narraciones orales les permiten, tanto a ellos como a los pobladores, ir comprendiendo la importancia de trabajar con materiales de su propia cultura para un aprendizaje significativo. 


\section{Imagen de un relato mítico}

Aquí presentamos la secuencia de imágenes o dibujos de un relato mítico:
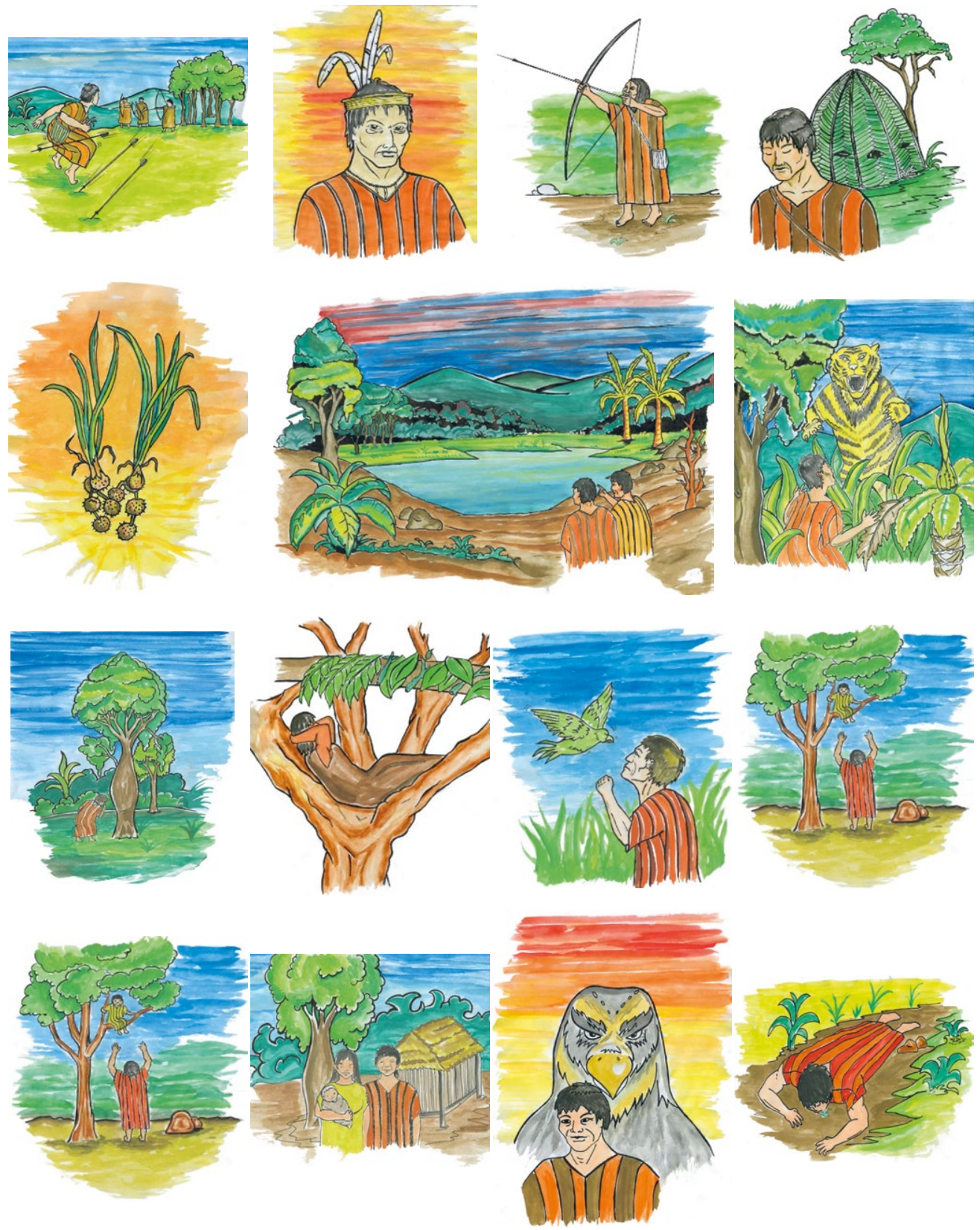

Dibujo: Camñari (asháninka). 
La secuencia de imágenes que presentamos, son relatos míticos que sucedieron en el espacio del valle del Perené y que el estudiante debe reconstruir con su propia versión.

Por lo tanto, la importancia de usar los materiales propia de la cultura asháninka va a permitir que los estudiantes tomen interés, estén motivados, se muestren participativos durante las sesiones de aprendizaje. Por otro lado, permite formar niños reflexivos y analíticos desde su propia cultura. También se va documentando y escribiendo las formas de aprendizaje del pueblo asháninka. Sin embargo, es preciso señalar que el grupo asháninka no tuvo escritura propia que permitiera documentar las manifestaciones culturales (Anderson 2002). A través de imágenes simbólicas representativas se explica el sentir y el pensar de la cultura asháninka (Vírhuez 2010).

\section{Narraciones asháninka como recurso para la lectoescritura}

Las narraciones según las estructuras orales asháninka es: frases de entrada (el inicio), seguidamente se podrá ver la estructura copiosa, redundante, con repeticiones de palabras, personificación, matiz agonístico (el intermedio o cuerpo), y cerrando el discurso narrativo, nos encontramos la frase de salida (el final).

Para la presente investigación se ha seleccionado dos relatos míticos Tisoni y Nabireri que los estudiantes podrán observar en imágenes y luego escucharlas. Los estudiantes tendrán que explicar lo que van visualizando en cada dibujo, allí se aplicará diversas estrategias para que los estudiantes desarrollen su habilidad cognitiva de reordenación. Luego, escucharán las narraciones y podrán analizar si lo que ellos mencionaron está considerado dentro de la narración oral original. Finalmente, los estudiantes identificarán y escribirán las oraciones que eran parte de la narración oral que escucharon y que no fueron parte de la descripción inicial que hicieron.

Se recomienda que:

- Todo material que se utiliza con los estudiantes se pegue dentro del aula para ir familiarizándolo cada día.

- Los materiales deben durar un mes y cada mes debe estar renovándose.

- Se debe tener las narraciones orales seleccionadas, solicitar a un sabio o la docente para que lo cuente y también se tiene que tener las imágenes. 


\section{Recomendaciones para el trabajo en la escuela}

Presento las siguientes recomendaciones para trabajar la lectoescritura audiovisual en la escuela. Las recomendaciones son:

- Cuando los estudiantes ya están en la escuela y comienzan a leer y escribir en su propia lengua materna, la familia debe reforzar en casa esos conocimientos que van adquiriendo en el ámbito escolar.

- La lectoescritura tiene que ser incorporada en los hábitos del niño como un acto voluntario que reporte placer y satisfacción, mas no como una obligación o deber.

- No se debe comparar la lectura y la escritura de un estudiante a otro.

- Cada lector tiene su propio ritmo de aprendizaje.

- Trabajar con diversas estrategias pedagógicas desde un enfoque intercultural, para asegurar los aprendizajes esperados de los estudiantes.

- El docente debe sentirse orgulloso de la labor que realiza y debe tener un objetivo esperado en los estudiantes. 


\section{Referencias bibliográficas}

AIDESEP. “Cosmovisión indígena amazónica”. En: Voz indígena (25), (2003): 10.

Anderson, Ronald. Historia de cambio de los ashéninka. Lima: Instituto Lingüístico de Verano, 2002.

Jacinto, Pablo. "Estructura Interna de los cuentos asháninka". (J. Garvich, \& A. Yanes, Edits.) En: Revista Peruana de Literatura (9 y 10). Julio de 2015, 143-153.

Jacinto, Pablo. "El narrar en asháninka: la oralidad del río y escuela" . En: Amazonía Peruana n 34. 2021.

Juárez, Daniel. Reconociendo narraciones miticas para la educación intercultural del pueblo asháninka. Lima: UNMSM, 2010.

Vílchez, Elsa. "La tradición oral entre los Asháninkas y los Machiguengas de la Amazonia peruana”. En G. Espino Relucé, Tradición oral, culturas peruanas: una invitación al debate. Lima: Fondo Editorial UNMSM, 2003, 191-199.

Vírhuez, Ricardo. Letras Indígenas en la Amazonía Peruana. Lima: Pasacalle, 2010. 